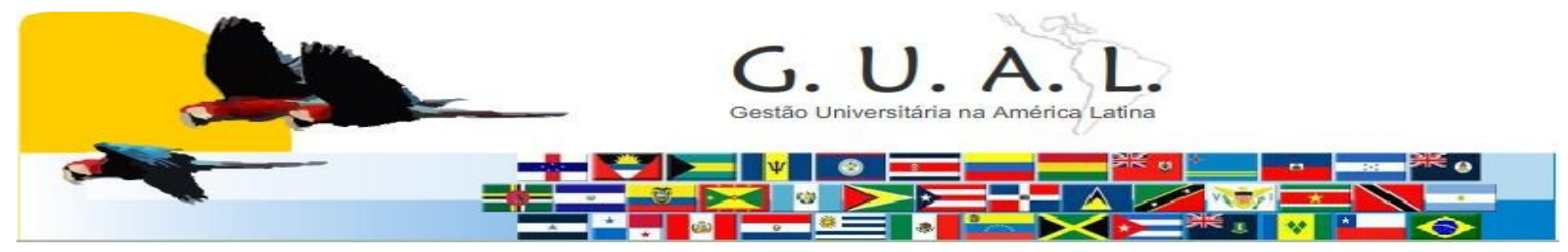

ISSN 1983-4535

\title{
AS INSTITUIÇÕES DE ENSINO SUPERIOR NO BRASIL: DESAFIOS E PERSPECTIVAS PARA OS GESTORES DO SÉCULO XXI - FUNDAMENTOS EM PEDRO DEMO E PIERRE BOURDIEU
}

\author{
HIGHER EDUCATION INSTITUTIONS IN BRAZIL: CHALLENGES AND \\ PROSPECTS FOR THE 21ST CENTURY MANAGERS - FUNDAMENTALS IN \\ PEDRO DEMO AND PIERRE BOURDIEU
}

Angela Maria Andrade Marinho de Souza, Mestre Instituto Federal de Educação, Ciência e Tecnologia Farroupilha angelamarinho.desouza@iffarroupilha.edu.br

Recebido em 30/outubro/2011

Aprovado em 23/janeiro/2012

Sistema de Avaliação: Double Blind Review Esta obra está sob uma Licença Creative Commons Atribuição-Uso. 


\title{
RESUMO
}

Este artigo trata dos desafios da Educação Superior Brasileira - fundamentos em Demo e Bourdieu referentes em especial a Universidade do século XXI. Apresenta o funcionamento deste nível de ensino, de forma dialética, tendo em vista os gargalos que dificultam fazer pesquisa e educação no Brasil, especialmente, que tenham resultados positivos para a sociedade evidenciando o compromisso social a partir de suas reais finalidades. Parte-se de um aporte teórico bibliográfico, cuja análise objetiva chamar a atenção dos gestores acadêmicos e demais profíssionais da Educação Superior, para a necessidade urgente de pensar a educação superior do século XXI, a função dos docentes e o perfil da Universidade, considerando os pressupostos do Paradigma Crítico. É importante discutir os rumos das Universidades Brasileiras e a formação dos novos profissionais. Investir em pesquisa e educação é investir em desenvolvimento. Daí o embate da comunidade científica em garantir a existência de um Conselho Deliberativo com a participação de todas as entidades científicas nacionais, para definir a destinação dos recursos e os rumos que a Universidade tomará neste terceiro milênio. A pesquisa que evidencie compromisso social com o seu entorno para se institucionalizar de forma adequada, requer conexão com o ensino e com a extensão.

Palavras-chave: Universidade. Compromisso social. Gestão acadêmica. Articulação ensino, pesquisa e extensão.

\begin{abstract}
This article discusses the challenges of Higher Education - Brazilian grounds on Demo and Bourdieu relating in particular to the University of the 21 st century. Displays the operation of this level of education, so dialectic, in view of the bottlenecks that hamper do research and education in Brazil, especially, that have positive results for society highlighting the social commitment from their real purposes. Part a bibliographic theoretical contribution, whose objective analysis to draw the attention of managers, academics and other professionals of higher education, to the urgent need to think about the higher education of the 21 st century, the role of teachers and the University's profile, given the assumptions of Critical Paradigm. It is important to discuss the direction of Brazilian universities and the training of new professionals. Invest in research and education is to invest in development. Hence the confrontation of the scientific community in ensuring the existence of a deliberative Council with the participation of all national scientific entities, to define the allocation of resources and the direction that the University will take in this third millennium. The research that reveal social engagement with his surroundings to institutionalize in an appropriate manner requires connection with education and with the extension.
\end{abstract}

Keywords: University. Social commitment. Academic management. Articulation teaching, research and extension. 


\section{INTRODUÇÃO}

O propósito deste Artigo é abordar alguns pontos relevantes sobre a estrutura e o funcionamento da Educação Superior Brasileira, prioritariamente, sobre as reais funções da Universidade no século XXI, especialmente no que se refere a uma abordagem crítica a partir das categorias abordadas por Pierre Bourdieu, em especial o conceito de homo academicus.

Por que uma abordagem crítica em Pierre Bourdieu? Com a morte deste renomado sociólogo francês em janeiro de 2002, desaparece mais uma das figuras que, no período após a II Guerra Mundial aliaram um pensamento inquieto e impiedoso à intervenção cívica e ao exercício da cidadania.

Acreditamos que assim como Bourdieu o sociólogo brasileiro Pedro Demo é sinônimo de intelectual comprometido com a educação verdadeiramente crítica. Ambos defendem a tese que não há democracia efetiva sem poder crítico.

Admirado por uns e detestado por outros, Bourdieu defende o caráter científico da Sociologia, é adversário do ensaísmo e inimigo dos 'intelectuais da mídia'. Vemos nele a voz da resistência científica em um momento de relativismo geral. É um crítico implacável dos privilégios garantidos e transmitidos por instituições; é autor de alguns dos livros sociológicos mais polêmicos dos últimos 40 anos, entre os quais Homo Academicus (1984). Tentou desmontar os mecanismos elitistas e corporativos das principais instâncias de poder no mundo contemporâneo: educação, cultura, posição na esfera estatal e mídia.

Da mesma forma Pedro Demo é um sociólogo brasileiro que tem mais de sessenta obras publicadas e que defende a educação reconstrutiva, sustentando que o "nível educacional se atinge quando aparece um sujeito capaz de propor, de questionar".

A apropriação da cultura como símbolo de distinção é um dos temas favoritos por meio do qual, Bourdieu, pretende pulverizar os modismos, o esnobismo e o vazio das elites. Quanto mais ataca, mais é legitimado como último baluarte do purismo intelectual em oposição à vulgaridade da indústria cultural. Criador ou disseminador de conceitos como 'campo' ou 'habitus', Bourdieu vê os homens em luta permanente pelo prestígio e pela ascensão social. Segundo críticos literários, o homem, para Bourdieu, não é o lobo do homem, mas o cão.

Frente às idéias e afirmações inquietantes e provocativas como as citadas anteriormente, pensamos que é preciso investigar o porquê isto acontece, uma vez que a função da Universidade, a partir da ação dos docentes universitários, é, ou deveria ser, a de 
formar profissionais que saibam aprender a aprender, ou seja, produzir conhecimento próprio e formar profissionais críticos para o exercício consciente da cidadania. Exercício este que se constitui pela e na criação de espaços de lutas sociais, em especial, aprender a ser e conviver, ou melhor, humanizar-se, privilegiando os princípios da dialética, da práxis educativa e formadora: o conhecimento praxiológico, assim denominado por Bourdieu.

Cabe, então, à Universidade como espaço político e cultural que é, formar para instituir, no Brasil, a democracia efetiva, tendo em vista que instituí-la não é tarefa fácil, dada a estrutura autoritária da sociedade brasileira. Posto isto, são feitas referências à qualidade do retorno social oportunizado pelos estudos dos mestres e doutores ao contexto social, uma vez que grande parte destes pesquisadores é bolsista ou recebe ajuda institucional da CAPES/CNPq e pouco se tem em termos de benefícios, retornos sociais que tragam a tona os problemas do corporativismo universitário em pleno século XXI.

\section{UM OLHAR HISTÓRICO E PEDAGÓGICO SOBRE A EDUCAÇÃO SUPERIOR NO BRASIL: OS DESAFIOS E AS PERSPECTIVAS}

Para Marilena Chauí, precisamos defender a Universidade, especialmente a pública, como um direito democrático, opondo-se a algumas medidas que visam o seu desaparecimento. No entanto, os pressupostos do debate precisam ser claros. Há uma confusão permeando conceitos essenciais que, muitas vezes, estão dando suporte ao discurso da manipulação, do adestramento e do absoluto.

É na Idade Média que, propriamente, aparece a Universidade identificando-se com sua sociedade e sua cultura, tornando-se efetivamente o órgão de elaboração do pensamento medieval. Ao longo dos séculos, observamos o esforço pela construção da Universidade européia que evidencia livre autonomia universitária, condição indispensável para questionar, investigar e propor soluções aos problemas levantados pela atividade humana.

É neste contexto, que aparecem os Cursos Superiores no Brasil, pois até 1808, data da chegada da família real, os luso-brasileiros faziam seus estudos superiores na Europa, especialmente em Portugal. Assim, na década de 1820, criam-se as primeiras Escolas Régias Superiores: de Direito em Olinda, de Medicina em Salvador e de Engenharia no Rio de Janeiro (MASSETTO, 2006).

Mister destacar que as Escolas Superiores nasceram em 1820, no entanto, o "Brasil pela colonização que teve, só conheceu Universidades em 1922. Isso significa dizer que temos 
quase nenhuma tradição universitária, porém a problemática universitária é grande e difícil" (MORAIS, 1995, p. 01).

Para um país que até a década de 1920, século XX, não contava com nenhuma Universidade, o Brasil apresenta, hoje, números importantes, Legislação específica e estrutura e funcionamento avaliados in loco pelo $\mathrm{MEC}^{5}$, além de avaliações externas que conceituam a qualidade dos Cursos Superiores. Mas, o que sabemos criticamente sobre os processo e políticas públicas de gestão universitária? Quem é o homo academicus?

Frente a estes dados é interessante perguntar: Qual é o modelo universitário inspirador das Universidades Brasileiras? Para Darcy Ribeiro, o padrão francês da universidade Napoleônica, ainda que não transplantado na sua totalidade, deu a essência as Universidade Brasileiras: Escolas autárquicas, supervalorização das ciências exatas, desvalorização das ciências humanas, departamentalização estanque dos Cursos, currículos seriados e programas fechados, etc.

Deste modo é relevante questionar: Qual é o papel da educação superior no novo contexto sócio-político do país-Século XXI? Qual é o papel da Universidade na sociedade brasileira diante das transformações na ciência, nas tecnologias e no mundo sócioprofissional? Qual é o papel da universidade na formação profissional hoje? E como a Universidade Brasileira se situa nesta formação? Enquadramento ao sistema mercantil, empregabilidade, competitividade, produtividade e utilitarismo, ou, humanização, reflexão crítica da realidade social, responsabilidade social e democracia critica? Muito ensino e pouca pesquisa ou muita pesquisa(produtividade) e pouco ensino? Universidade enquanto espaço de formação e de produção do conhecimento? Ou Universidade enquanto lócus de discussão das grandes temáticas da vida cotidiana? Universidade enquanto tendência para a consolidação de funções instrumentais? Qual é o sentido social das pesquisas? Como o ensino, a pesquisa e a extensão participam na formação de futuros profissionais e se inserem nestes novos tempos? Qual é o papel da Universidade e de suas atividades de extensão? Como compatibilizar o avanço da ciência e da técnica com a simultânea ampliação das desigualdades sociais? Como compatibilizar o atendimento às necessidades e demandas regionais e locais e ao mesmo tempo sintonizar com a globalização, suas demandas e interesses pretensamente hegemônicos? São muitas as inquietações e poucas as respostas. Que análise sociológica faria Bourdieu?

Pode-se dizer que a Educação Superior Brasileira é marcada pela hegemonia econômico-política do neoliberalismo e de sua expressão social-democrata, ou seja, "a 
polarização entre a carência e o privilégio exprime a existência de uma sociedade na qual o espaço público não consegue instituir-se" (CHAUÍ, 2001, p. 13).

A verdade é que a Educação Superior tem como finalidade a criação, o cultivo, a difusão e a aplicação dos saberes, mais complexos e sistêmicos, já elaborados pela humanidade ao longo de sua particular trajetória histórica, desde a Antiguidade até a Pós Modernidade. Entretanto, segundo Vieira (1995), não podemos confundir Universidade com os demais estabelecimentos de ensino superior, visto que a Universidade (e agora os Institutos Federais de Educação) é uma instância privilegiada da produção do saber. Para Regis de Morais (1995), cabe a educação universitária preocupar-se com a consciência da Ciência; compete-lhe esclarecer histórica e sociologicamente as relações complexas entre o saber e o poder, oferecendo condições para que sejam compreendidas epistemologicamente as relações entre prática científico-tecnológica e responsabilidade social.

O poder acadêmico refere-se ao grau de controle sobre a organização, mecanismos de formação de professores, a seleção, promoções e carreiras, enquanto o intelectual renome se refere ao reconhecimento pelo público mais vasto educados para trabalhos publicados. Professores, por isso, são diferenciados em termos de mercados culturais onde fazem seus principais investimentos. Como isso acontece no cenário universitário Brasileiro?

A Dicotomia nos campos intelectual continua com a diferenciação entre economia de capital (riqueza, renda, a propriedade) e capital cultural (conhecimento, cultura, educação credenciais). Bourdieu chama economia capital o princípio da hierarquia dominante, enquanto que o segundo é o segundo princípio da hierarquia. É de Bourdieu a tese de que estes dois créditos para poder competir internamente devem diferenciar no sistema francês, a ideia de educação como bem público.

Neste sentido, Goethe (In VIEIRA, 1995, p. 29) diz:

[...] o estadista, o padre, o pregador da moral sempre apelam para a mentira piedosa - mentem, mentiram ou mentirão por força de seu próprio ofício. Como é possível à universidade, instituição supostamente voltada para a busca do belo, do bom, do verdadeiro, relacionar-se com os poderes mencionados?Os acadêmicos são capazes de palavra específica, ou apenas constituem redes de ampliação para os sofismas dominantes?Qual o real significado da Universidade enquanto órgão do poder estatal (ou das Igrejas)e das classe hegemônicas?Um professor, ou aluno, é dotado de poder?

É importante lembrar que na comunidade acadêmica o fim de todos é, ou deveria ser, o universal. No entanto, paradoxalmente, essa forma de poder pelo reconhecimento universal 
é uma das pouquíssimas coisas que unem, de fato, o poderoso e o acadêmico. Ambos desejam ser ouvidos e aplaudidos. A diferença é que o intelectual acadêmico, o sábio, pouco proveito pode tirar do seu saber, do seu poder, porque as massas ignorantes o ignoram, visto que o poder pouco tem a ver com conhecimento e muito tem a ver com aparência. Esta é, no nosso entendimento, uma implicação a ser superada e uma possibilidade a ser construída imediatamente no contexto universitário. É preciso ter claro que a Universidade não é lugar de poder, mas da autoridade do argumento (Demo, 2005) que vem justamente dos seus vários saberes.

Conhecer a legislação que dá suporte a educação superior é um exercício de responsabilidade profissional, porque permite compreender melhor o espaço universitário onde se trabalha. Uma tomada de consciência sobre a legislação é uma possibilidade séria de buscar o reconhecimento da importância da Universidade a margem das agruras sociais contemporâneas.

Sabemos que as origens da Universidade remontam à Idade Média, mas não é possível que em pleno século XXI continuem com ações fechadas como antes, visando atender aos interesses desta época. A Universidade atual precisa atuar no contexto da Modernidade, inovando em suas ações, erradicando seus vícios seculares e oportunizando conhecimento próprio de vanguarda que beneficie a sociedade.

As Universidades, atualmente, colocam-se para a sociedade a partir de um modelo bem caracterizado. A Universidade Russa, por exemplo, objetiva servir o Estado. Já a Universidade Inglesa tem um perfil marcado pelo Humanismo, enquanto que a Universidade alemã busca a investigação. A Universidade Americana, de caráter Positivista, tem seu ponto forte no desenvolvimento científico e tecnológico. Na Argentina o modelo de Universidade é variado e eclético, pois apresentam perfis populares, elitistas e alguns que visam o mero lucro. E a Universidade Brasileira? Qual é o seu perfil? Como se caracteriza a partir de suas reais ações e intenções? Quais diferenças existem entre as Universidades Públicas e as Universidades Privadas no Brasil? Quem está fazendo a diferença neste início de milênio? Por quê?

Enfim, a verdade é que a Universidade está em crise, e por crise, ao considerar a origem grega da palavra, entendemos abismo. Assim, é correto afirmar que a Universidade, especialmente a Brasileira, está à beira do abismo ou já caiu nele sem perceber o fosso em que se encontra (CASTANHO, 2000, p.15). 
Neste sentido, Boaventura de Souza Santos (2005) fala da tríplice crise da Universidade como sendo: Institucional, de hegemonia e de legitimidade.

Assim, é relevante dizer que, para Bourdieu, o homem é uma produção social, que deve ser analisado através de um processo de causalidade circular, que articula níveis diferentes da realidade separados precedentemente pela micro e a macro sociologia. Duas noções são bem exploradas nos seus trabalhos na articulação das duas instâncias que sustentam o mundo social: campos sociais e habitus. A relação entre estas duas instâncias faz com que as estruturas se tornem corpo, mas igualmente que o corpo se faz estrutura.

A partir desta perspectiva e armado com outros conceitos, como legitimidade (já citado por Boaventura), estratégia, classe social, interesse, capital simbólico, Bourdieu avança em vários domínios da sociedade, campos sociais, e faz seu combate sociológico. Entre os vários campos sociais analisados, podemos destacar dois, o campo de produção intelectual (homo academicus) e o campo de produção jornalístico.

Refutando dogmas e mitos a cerca daqueles que analisam a realidade, Bourdieu investe no sujeito da ciência como parte do objeto da ciência, afastando a ilusão de "intelectuais sem laços nem raízes", uma forte ideologia arraigada no mundo intelectual. Sua análise infiltra-se no interior da dinâmica acadêmica e busca caracterizá-la pelos interesses específicos (postos acadêmicos, contratos de edição, reconhecimentos e gratidões), na maioria das vezes imperceptíveis aos olhos daqueles que não fazem parte deste universo.

Bourdieu ressalta, num olhar amplo sobre este campo, que "os intelectuais são, enquanto detentores de capital cultural, uma fração (dominada) da classe dominante, e muitas de suas tomadas de posição, em matéria de política, por exemplo, devem à ambiguidade de sua posição de dominados entre os dominantes". Tal afirmação pode encontrar ricos estudos de caso, seja no Brasil, na França, na Rússia como na China.

Esta ambígua relação de poder faz com que muitos intelectuais se apropriem de uma competência que extrapola seus reais limites de competência, fazendo apelo aos títulos escolares, num resgate similar aos títulos de nobreza de outrora, ou melhor, eles se tornam os títulos da nobreza de hoje, transformando-os, com frequência, em passaporte para se tornarem a "Nobreza do Estado" contemporâneo. Esta apropriação é acompanhada por um outro tipo de usurpação, o que o torna uma autoridade acerca de temas que extrapolam a competência técnica de certos intelectuais. 
As inquietações e algumas explicações Bourdinianas estão registradas. A partir de agora, além de refletir criticamente sobre algumas abordagens, acreditamos necessário tecer algumas considerações afins.

Do ponto de vista pedagógico, como deve ser entendida a palavra Curso em uma Universidade? Como suas raízes vem do latim currere e lembra o verbo correr, fazer um curso significa que os discentes devem deslocar-se com rapidez dentro de um currículo científico e demonstrar aprendizagens críticas condizentes em cada fase a ser vencida visando à "conquista" do Diploma, a fim de evidenciar no contexto social trabalho competente, de qualidade mostrando que sabe analisar e atuar no seu entorno de forma crítica.

Temos, então, os Cursos de Graduação, onde se apoia praticamente todo o Ensino Superior, pois são estes que oportunizam a formação de profissionais de nível universitário em todos os ramos do conhecimento. Temos, também, os Cursos de Pós-Graduaçãa que se estruturam por meio de currículos formais resultantes dos diferentes campos do saber com duração diferenciada. Aqui aparecem os Cursos latu sensu - as especializações e os Cursos strictu sensu - mestrados e doutorados. Temos, ainda, com a valorização social das Universidades os Cursos de Extensão que passam a ter relevância nas programações acadêmicas. Estes podem ser ministrados tanto dentro das Universidades, quanto fora, a partir de convênios. Todavia, é de pensar: Quais benefícios as programações universitárias tem evidenciado no entorno social?

Vale ressaltar que esses Cursos podem ser ministrados em diferentes Instituições de Ensino. Dentre as quais, em Universidades, por serem Instituições Pluridisciplinares e reconhecidas desde a Idade Média (Século XII e XIII), atuando na formação dos quadros profissionais de nível Superior, de Pesquisa, de Extensão. São detentoras do domínio e cultivo do saber humano, e têm as seguintes características próprias: produção intelectual institucionalizada, pelo menos um terço do corpo docente com titulação acadêmica de mestre ou douto, no mínimo um terço do corpo docente com regime de tempo integral entre outras.

Nesta lógica, é de questionar porque tantos méritos para a Universidade e pouco reconhecimento e incentivo para as demais Instituições de Ensino Superior? Será que em algumas Instituições a qualidade e o retorno social não é igual, ou melhor, que na própria Universidade, em especial, a pública? A citar o exemplo de alguns Centros Universitários, de algumas Fundações de renome e a estrutura invejável dos Institutos Federais de Educação, 
Ciência e Tecnologia ${ }^{1}$ e de algumas Faculdades, que apesar de não usufruírem das prerrogativas e méritos da Universidade e dos Institutos Federais de Educação, oportunizam formação acadêmica de excelência.

De acordo com a Constituição Federal de 1988, as Universidades gozam de autonomia didático-científica, administrativa, de gestão financeira e patrimonial e obedecerão ao princípio da indissociabilidade entre ensino, pesquisa e extensão. Daqui decorre uma das muitas necessidades do Plano de Desenvolvimento Institucional - PDI. Que Plano é este? De que forma é construído? Quem é chamado a participar das discussões? As suas metas e objetivos referem-se a que público?Existe transparência nas ações? Ex: Quem se beneficia na Universidade Pública, em especial de Programas de Mestrado e Doutorado? Os critérios estabelecidos pelo Colegiado para seleção dos novos pesquisadores são claros e transparentes ou ainda existem marcas do corporativismo?

A verdade é que, como diz Demo, "a Universidade já não sabe mais o que é ciência, e talvez nem educação" (1996, p. 138). O fato é que a presença do professor improdutivo, aquele que apenas ensina na Universidade, está contribuindo para que a passos largos esta instituição caia na ordem da sucata. $\mathrm{O}$ certo é que a crise concentra-se na falta de mérito acadêmico, no ensaísmo e na vulgaridade da indústria cultural. Pontos estes, tão criticados por Bourdieu (BONNEWITZ, 2006).

Em sua obra, Homo Academicus, Bourdieu adverte que conscientemente excluiu informações anedóticas ao analisar as tendências e as tensões do Ensino Superior Francês, com particular atenção para os protestos de estudantes conhecidos como maio de 1968 . Assim, pensamos que é relevante analisar as tensões e tendências do Ensino Superior Brasileiro desta mesma forma, já que, no nosso entendimento, alguns “ensaístas” ao analisar a crise da universidade Brasileira, descartam informações relevantes para o exercício da cidadania democrática. Vemos como extrema necessidade, que sociólogos brasileiros, admiradores das ideias de Bourdieu, escrevam sobre a Universidade Brasileira no século XXI, enfocando suas mazelas em uma perspectiva crítica, apontando perspectivas com enfoque Marxiano. Não podemos admitir que formas simplificadas de argumentação aflorem o estruturalismo subjacente a Teoria de Bourdieu.

\footnotetext{
${ }^{1}$ Para Eliezer Pacheco, pensar os Institutos Federais de Educação, do ponto de vista político, representa a superação de visões reducionistas e a instituição de uma política pública que concorra para a concretização de um projeto viável de nação para este século.(2010, p.17)
} 
É relevante lembrar a influência desmesurada que certos aparelhos ideológicos, ao usar conscientemente pessoas alienadas, acabam exercendo no campo cultural e científico. "Campo" é um dos conceitos básicos de Bourdieu, que significa uma configuração de relações objetivas entre posições de agentes ou de instituições. Esta configuração constitui o campo, ao mesmo tempo em que é constituída por ele. Conceito de caráter descritivo o "campo" adquire também um valor normativo: é a formação de um campo autônomo, que permite que regule a si mesma. Muito concretamente, faz com que as modalidades de consagração dependam das relações estabelecidas no próprio campo e não sejam impostas de fora, pelo dinheiro ou pelo Estado. O mesmo vale para o campo acadêmico.

A despolitização e a falta de rigor acadêmico desarranjam esta situação. A presença do analfabeto funcional, por exemplo, se torna um atalho para a consagração, não apenas junto ao público leigo, o que seria menos grave, mas dentro do próprio campo, afetando a distribuição do capital simbólico e, por tabela, questões como a publicação de artigos ou livros e o financiamento público à pesquisa. A falta de conhecimento, portanto, coloniza os campos artístico e científico, impondo critérios que lhes são estranhos e revertendo uma autonomia duramente conquistada em face dos poderes econômico e político. Poderes dos quais, por sua vez, a Universidade é em alto grau dependente. Estas influências representam desta maneira, uma revanche à autonomização dos campos intelectuais.

Contra a ameaça que a falta de conhecimento representa, é interessante dizer que esta promove uma espécie de violência simbólica ( FLACHSLAND, 2005) e que está por trás de algumas consagrações intelectuais. Trata-se de um passo atrás nas reflexões críticas de Bourdieu, pois as imposições da vulgarização não autorizam nem justificam uma Universidade internada numa "torre de marfim", que afaste dela todo o público especializado.

A análise dos efeitos sociais da Universidade é antiga; sua investigação sobre a forma de funcionamento também se limita a reproduzir velhos enunciados. De fato, o esforço do sociólogo francês é muito mais o de traduzir para as suas próprias categorias o que outros, já haviam dito ou apenas pensado sobre a Universidade.

No entanto, o escopo da Universidade é tal que a ausência de originalidade não é uma falha. Como pública que procurou ser, obteve êxito total, ocupando por vários anos a lista de best-sellers.

Importante também saber que a Lei de Diretrizes e Base para Educação Nacional $\mathrm{n}^{\circ}$ 9394/96 - Brasil no artigo 53 define: 
[...] no exercício de sua autonomia ${ }^{2}$, são asseguradas as Universidade, sem prejuízo de outras, as seguintes atribuições:

I - criar, organizar e extinguir, em sua sede, cursos e programas de educação superior previstos nesta Lei, obedecendo às normas gerais da União e, quando for o caso, do respectivo sistema de ensino;

II - fixar os currículos dos seus cursos e programas, observadas as diretrizes gerais pertinentes;

III - estabelecer planos, programas e projetos de pesquisa científica, produção artística e atividades de extensão;

IV - fixar o número de vagas de acordo com a capacidade institucional e as exigências do seu meio;

V - elaborar e reformar os seus estatutos e regimentos em consonância com as normas gerais atinentes;

VI - conferir graus, diplomas e outros títulos;

VII - firmar contratos, acordos e convênios;

VIII - aprovar e executar planos, programas e projetos de investimentos referentes a obras, serviços e aquisições em geral, bem como administrar rendimentos conforme dispositivos institucionais;

IX - administrar os rendimentos e deles dispor na forma prevista no ato de constituição, nas leis e nos respectivos estatutos;

$\mathrm{X}$ - receber subvenções, doações, heranças, legados e cooperação financeira resultante de convênios com entidades públicas e privadas.

Parágrafo único. Para garantir a autonomia didático-científica das universidades, caberá aos seus colegiados de ensino e pesquisa decidir, dentro dos recursos orçamentários disponíveis, sobre:

I - criação, expansão, modificação e extinção de cursos;

II - ampliação e diminuição de vagas;

III - elaboração da programação dos cursos;

IV - programação das pesquisas e das atividades de extensão;

$\mathrm{V}$ - contratação e dispensa de professores;

VI- planos de carreira docente.

Art. 54. As universidades mantidas pelo Poder Público gozarão, na forma da lei, de estatuto jurídico especial para atender às peculiaridades de sua estrutura, organização e financiamento pelo Poder Público, assim como dos seus planos de carreira e do regime jurídico do seu pessoal .

$\S 1^{\circ}$ No exercício da sua autonomia, além das atribuições asseguradas pelo artigo anterior, as universidades públicas poderão: I - propor o seu quadro de pessoal docente, técnico e administrativo, assim como um plano de cargos e salários, atendidas as normas gerais pertinentes e os recursos disponíveis; II elaborar o regulamento de seu pessoal em conformidade com as normas gerais concernentes; III - aprovar e executar planos, programas e projetos de investimentos referentes a obras, serviços e aquisições em geral, de acordo com os recursos alocados pelo respectivo Poder mantenedor; IV - elaborar seus orçamentos anuais e plurianuais; $\mathrm{V}$ - adotar regime financeiro e contábil que atenda às suas peculiaridades de organização e funcionamento; VI realizar operações de crédito ou de financiamento, com aprovação do Poder competente, para aquisição de bens imóveis, instalações e equipamentos; VII - efetuar transferências, quitações e tomar outras providências de ordem orçamentária, financeira e patrimonial necessárias ao seu bom desempenho. $\S 2^{\circ}$ Atribuições de autonomia universitária poderão ser estendidas a

${ }^{2}$ Para Suasnabar, la autonomia universitária, a pesar de ser un precepto constitucional no és una realidad de las universidades publicas federales del Brasil (2005, p.63-64) 
instituições que comprovem alta qualificação para o ensino ou para a pesquisa, com base em avaliação realizada pelo Poder Público.

Questiona-se: que autonomia? Qual transparência nas ações? É possível questionar a legitimidade de uma eleição: a gestão acadêmica é politizada ou partidarizada? Existe politicidade ou politicagem na composição dos quadros gestores? Entendemos politicidade em Demo(2002) como a habilidade humana de alargar as oportunidades de vida, tomando em conta as circunstâncias dadas. Politicidade é o signo da autonomia, uma habilidade que se constrói através de processos mais profundos de aprendizagem e conhecimento, além da prática vivenciada. Segundo Demo, para positivistas e neoliberais, politicidade é noção espúria, confundida com politicagem. $\mathrm{O}$ autor concorda que não falta politicagem entre docentes que se dizem críticos, até porque é comum que "críticos" e "neoliberais" façam na escola a mesma coisa: aula instrucionista.

Deste modo, é importante abordar as funções da Universidade e os seus desafios, para que aprendamos a diminuir a distância entre o que ensina e a prática que a vida exige. Compete à Universidade dar início às mudanças indispensáveis para atender às solicitações da sociedade atual, que implora por desenvolvimento, por práticas transparentes e democracia efetiva. Na verdade é um compromisso ético com a estimulação do correto exercício da cidadania, frente a formação dos futuros profissionais, futuros dirigentes sociais. Sabemos das influências globais que sofre a universidade, entretanto, essa instituição não deve acomodar-se e sim dedicar-se a pesquisa, a produção, as atividades de investigação de forma que através dos grupos de estudo e pesquisa a realidade seja problematizada, e as verdades que mudam concepções sobre o universo e sobre si mesmo sejam buscadas e divulgadas imediatamente.

A Constituição Federal no seu artigo 207 assegura a indissociabilidade entre Ensino, Pesquisa e Extensão. Todavia, essa trilogia precisa ser revista, por que a alma da vida acadêmica é constituída pela pesquisa. Para Demo "quem não pesquisa, nada tem a ensinar, pois apenas ensina a copiar" (1996, p. 128). É fundamental, portanto, “ensinar” a pesquisar, ou seja, só aprende quem aprende a aprender. Quanto ao ensino, não há dúvida, pois podemos dizer que é e sempre será a função axial das Instituições de Educação Superior.

O Ensino Superior, dada à extrema complexidade que envolve as peculiaridades das Ciências Exatas, Humanas, Sociais ou Aplicadas, exige que os gestores do pedagógico sejam preferencialmente mestres ou doutores, especialistas com larga experiência na área, ou ainda que comprovem sucesso na carreira, tendo algo de proveitoso para oferecer aos seus alunos. Assim, espera-se que o docente da Educação Superior oportunize conhecimento de vanguarda 
aos seus alunos, que esteja atualizado em relação ao seu tempo, que faça uso didáticopedagógico das modernas tecnologias, que utilize-se de diversificadas bibliografias atualizadas na sua área e não dispense jamais as possibilidades de formação continuada através da participação em Simpósios, Congressos, atuando preferencialmente como autor, palestrante, mediador, defensor de Tese própria, pesquisador etc.

$\mathrm{Na}$ verdade, na Universidade e nos Institutos Federais de Educação, o Ensino e a Pesquisa devem ser cara e coroa de uma mesma moeda, porque o professor (aqui entendido como gestor do pedagógico) que não pesquisa, pouco tem a ensinar. Já, os Centros Universitários e as Faculdades podem legalmente oferecer apenas o ensino. Mas aí residem alguns questionamentos: como ensinar sem pesquisar? Como "ensinar" sem produção própria? Será que não existem bons pesquisadores fora do contexto universitário?

Temos o gestor do pedagógico que faz a opção pelo ensino e aquele que faz a opção pela pesquisa e de acordo com Pedro Demo, aquele professor que faz a opção somente pelo ensino passa a vida contando aos alunos o que aprendeu de outrem, contentando-se em imitar e reproduzir subsidiariamente o saber e isto deve ser combatido. Para o autor isto pode ser visto

\begin{abstract}
no fato tão comum de professores que, uma vez galgando a posição de pesquisador eminente, já não tem mais interesse em trabalhar com alunos. No jargão universitário, pesquisador tende a não dar mais "aula", porque imagina estar perdendo seu tempo. Na verdade, o pesquisador é quem, acima de tudo, deveria manter contato com o aluno, sendo esta a mensagem mais pertinente de um programa como o Pibic (bolsa de iniciação científica para estudantes, do CNPq). Quando se perde a percepção do valor pedagógico da pesquisa, resta apenas o apego metodológico, tornando a universidade uma "fábrica do conhecimento"(Aronowitz: 2000). Entre nós, sequer ocorre isso, porque a "fábrica" é apenas de aulas instrucionistas, tendencialmente. Mas existe também o disparate contrário. Muitos professores continuam mantendo a noção de que "contato pedagógico" exemplar é a aula, ignorando sua face autoritária e disciplinar, sonsamente. A aula instrucionista é, na prática, contato nenhum, porque aí não se negociam argumentos, negociam-se apenas prepotências. Embora pesquisa não possa ser vista como panaceia - é uma estratégia de formação e aprendizagem entre inúmeras outras - detém enorme potencialidade formativa, desde que o docente saiba aproveitar esta chance (DEMO, 1996).
\end{abstract}

Já por Extensão, devemos entendê-la como a $3^{\text {a }}$ função inerente ao conceito de Universidade. É uma ponte ente a Universidade e todos os setores da sociedade. Entretanto, ressaltamos que as atividades de extensão não são atividades extracurriculares, geralmente são dirigidas a públicos externos a Universidade. E, por ter viés social e comunitário, as 
atividades de extensão ajudam na formação positiva da imagem institucional. A extensão Universitária acontece sob a forma de cursos, serviços, difusão de resultados de pesquisa etc.

È mister ressaltar que, em pleno século XXI, as Universidades estão convocadas a participar da solução dos numerosos problemas que atravessa a humanidade. E para isto, a extensão a partir, do ensino e da pesquisa é a forma mais moderna e flexível para exercer estas funções educacionais e sociais, essenciais a este terceiro milênio. Entretanto, lembramos que a Universidade não pode mais contentar-se "com repasse subalterno para gente subalterna" (DEMO, 1996, p.136).

As Universidades Brasileiras precisam entender que o modelo de ensino fechado que atendeu muito bem os interesses da sociedade do século XII, data de nascimento medieval das Universidades, já não servem mais aos novos tempos. Quando falamos em conhecimento avançado, a Universidade deve ser a primeira Instituição a dar exemplo de vanguarda. A pesquisa, que é inseparável do ensino, torna-se caminho privilegiado para a produção e verdadeira construção crítica do saber, a partir da construção de uma política científica séria.

Neste sentido, ainda de acordo com Demo (1996), educar pela pesquisa significa se postar contra a ignorância, pois ambas valorizam o questionamento, dedicam-se ao processo reconstrutivo (base da competência renovada), incluem a confluência de teoria e prática, pois elas (educação e pesquisa) se opõe aos procedimentos manipulativos e principalmente condenam a cópia, porque esta consagra a incompetência e a mediocridade.

Neste contexto, por pesquisa leia-se atividade acadêmica voltada para a solução de problemas através do uso de processo científico. É importante ressaltar que as pesquisas devem ter início, meio e fim, e se classificam de acordo com a sua metodologia. O certo é que, pesquisa e ensino devem andar juntos, no entanto, dados revelam que na maioria das Universidades, é dada mais atenção ao ensino ou a pesquisa.

Sabemos que as finalidades básicas da CAPES são: introdução dos critérios internacionais de qualidades; ajustamento dos parâmetros e indicadores adotados com a valorização da produtividade docente e discente; avaliação por programa da pós-graduação e não mais por curso de mestrado ou doutorado; periodicidade trienal para a avaliação geral do sistema; adoção da escala numérica para a conceituação dos cursos para validação de diploma pelo MEC. A Pós-Graduação, como coroamento da Educação Superior, refere-se à conquista do mais alto nível de competência científica, em especial, quando se trata de Cursos Strictu Sensu, já que estes têm por objetivos formar com rigorosa seletividade intelectual, professores de renomes, cientistas e pesquisadores. Contudo, lamentamos que a CAPES não tenha 
conseguido avaliar, apoiar e credenciar para funcionamento novos programas de Mestrados e Doutorados no Brasil. O que faz com que muitos profissionais sérios por falta de atendimento a demanda interna busquem seus mais nobres títulos no exterior. Em muitos currículos brasileiros de renome, observamos a formação de mestres e doutores na Argentina, nos Estados Unidos, na Espanha, na Alemanha entre outros. Assim perguntamos: por que tanta gente buscando crescimento intelectual fora do País?

O que Mestrandos e Doutorandos buscam é o aprofundamento da formação cultural, científica e profissional, e enquanto o mestrando volta-se mais para a formação de professores de Escolas Superiores; do doutorando exige-se maior envolvimento com a pesquisa. Talvez estas buscas não atendam os interesses políticos de alguns neoliberais que estão no "poder". Por isso, tantos entraves para aceitação de projetos de pesquisas que tratam diretamente dos problemas socio-educacionais emergentes. A globalização está a exigir na área de gestão um ensino mais ágil, de credibilidade e de qualidade, uma vez que a formação Universitária tradicional, não está dando suporte suficiente a atual Sociedade Intensiva do Conhecimento.

Sabemos da relevância da pesquisa, mas sabemos também da enorme carência dos recursos para essa modalidade de atividade, e também dos entraves internos para que um novo pesquisador apareça no cenário nacional. Quando levantamos esta questão não estamos fazendo, somente, referências aos privilégios corporativistas que retorno algum trazem para o meio social. Estamos, sim, fazendo referências aos pouquíssimos jovens iniciantes na pesquisa que estão contribuindo para melhorias no contexto social maior.

É impossível deixar de mencionar a questão das desigualdades regionais, bem como as condições impostas as Universidades e pesquisadores para a concessão de bolsas. Sem fomento e com parcos subsídios como fazer pesquisa? Ficam alguns questionamentos: Quem pode ser pesquisador? Qual seu perfil? Onde pode ser enquadrado? Quem trabalha com C\&T no Brasil sabe que as atuais políticas públicas precisam urgentemente ser revistas. Em pleno Século XXI, as ações são como as do Século XIII. Os programas de pesquisa são fechados, visam mais os interesses próprios e particulares da cada Universidade do que os interesses coletivos. É o corporativismo em ação. Isso precisa mudar!

Assim, ao propor o estudo da noção de campo na obra de Pierre Bourdieu, bem como das formas de apropriação e de incorporação de suas proposições nos estudos do campo educacional brasileiro, pretendemos refletir sobre a presença, as configurações e o papel desempenhado pelo conceito na explicação do mundo social tal como o autor o arquitetou. Tentamos apresentar as características das apropriações realizadas do pensamento de 
Bourdieu no Brasil, mediante a análise dos textos nos quais há referências ao autor, incorporação de conceitos e/ou assimilação do seu modo de trabalho.

Uma incursão analítica pela obra de Bourdieu em busca da origem, transformações e permanência do conceito, pode ser de grande utilidade aos estudiosos que procuram valer-se do mesmo em suas pesquisas na área de ciências humanas ao explicitar as especificidades e o alcance da noção de campo. A ideia das múltiplas possibilidades de recurso ao autor (e ao conceito de campo) enseja a concretização de análises bastante diversificadas. Outra especificidade vem a ser o detalhamento das apropriações do pensamento de Bourdieu no campo educacional brasileiro por meio da análise de livros, artigos, teses e dissertações que utilizaram o autor como referência para suas investigações.

Aspectos centrais necessitam ser estudados para a compreensão do arcabouço epistemológico do trabalho sociológico de Bourdieu: o conceito de prática (ou o conhecimento praxiológico) e as noções de habitus, de campo e de homus academicus. É a essa concepção de espaço social e acadêmico que Bourdieu vai sobrepor a noção de campo, articulada às de habitus e de prática. Nesse sentido, assim como as primeiras experiências dos atores sociais vividas no ambiente familiar, isto é, o habitus adquirido nas relações familiares é condição primordial para a estruturação das experiências escolares, o habitus transformado pela ação escolar constitui o princípio de estruturação de todas as experiências ulteriores, incluindo desde a recepção das mensagens produzidas pela indústria cultural até as experiências profissionais.

De acordo com Catani (2002), Bourdieu, ao criticar o objetivismo e o conhecimento fenomenológico, formula outro modo de conhecimento, inicialmente denominado "praxiológico", cujo objetivo é articular dialeticamente estrutura social e ator social.

\section{CONCLUSÃO}

Os estudos das obras de Bourdieu, no Brasil, na área da educação foram peculiares: ele foi transformado num pedagogo ou num filósofo educacional cuja pedagogia devia ser rejeitada em nome dum humanismo otimista que era justamente o que ele estava criticando. Sua obra acabou aprisionada nas dicotomias que ele tanto combateu: enclausurou-se a sua sociologia no paradoxo "reprodução versus transformação", dualidade esta que na época fez enorme sucesso no campo educacional, sem, contudo, operar na prática as mudanças necessárias e urgentes, pois mexeria com os interesses da classe burguesa. 
Embora possamos dizer que, durante anos, a leitura de Bourdieu, no Brasil, concentrou-se em $A$ reprodução, convém lembrar que, a partir de meados da década de 80 , os estudos que nele se apoiam e dele se apropriaram passaram a revelar maior familiaridade com sua obra, incorporando outros títulos e contribuições do sociólogo.

Apoiar pesquisas, incentivar leituras inovadoras e críticas que podem trazer benefícios a uma Nação é muito mais louvável do que, apoiar as mesmices de sempre; daqueles que não querem perder seus lugares cristalizados, assegurados por práticas individualistas e corporativas, que, ao longo dos anos, tem contribuído para que muitas Universidades portemse mais como castelos medievais do que como promotoras de conhecimentos avançados, Ciência e produção cientifica próprias.

É importante discutir os rumos das Universidades no Brasil e, por conseguinte, a f a atuação dos gestores acadêmicos bem como a formação dos novos profissionais, especialmente dos pesquisadores e escritores, haja vista que a tendência é a exclusão dos mais críticos. Ter um projeto de pesquisa aprovado no Brasil é algo bastante questionável, pois a sistemática adotada pelo CNPq é a avaliação pelos pares. Infelizmente o paradoxo é no mínimo intrigante.

É evidente que a locação de recursos orçamentários da União é uma questão política. Investir em pesquisa e educação é investir em desenvolvimento. Daí decorre um questionamento: Qual é o interesses dos governantes em investir em desenvolvimento, a partir de estudos científicos? Neste contexto, o embate da comunidade científica é justamente garantir a existência de um Conselho Deliberativo com a participação de todas as entidades científicas nacionais, para definir a destinação dos recursos e os rumos que a Universidade e os Institutos Federais tomarão neste terceiro milênio?

A ideia geral deste artigo pode ser resumida no pensamento de Demo (2000) quando fala da característica emancipatória da educação, o quê exige a pesquisa como método formativo, pela razão principal de que somente um ambiente de sujeitos gesta sujeitos. Entre educação e pesquisa há um trajeto coincidente, que podemos assim sugestivamente codificar: ambas se postam contra a ignorância; ambas valorizam o questionamento, marca inicial do sujeito histórico; ambas se dedicam ao processo reconstrutivo; ambas incluem a confluência entre teoria e prática, por uma questão de realidade concreta; enquanto a pesquisa busca na prática a renovação da teoria e na teoria a renovação da prática, a educação, encontra no conhecimento a alavanca crucial da intervenção inovadora, agregando-lhe sempre o compromisso ético; ambas se opõem terminantemente à condição de objeto, por ser a negação 
da qualidade formal e política; ambas se opõem a procedimentos manipulativos, porque estes negam o sujeito; enquanto a pesquisa supõe ambiente de liberdade de expressão, crítica e criatividade, a educação exige a relação pedagógica interativa e ética, marcada pela qualidade formativa; ambas condenam a cópia, porque esta consagra a subalternidade.

Como uma das alternativas possíveis para o século XXI, defendemos a pesquisa que evidencie compromisso social com o entorno institucional para se legitimar de forma adequada em permanente conexão com o ensino. O que ocorre, no entanto, é que mudanças de políticas de governo afetam com frequência sua viabilidade e determinam, assim, o sucesso ou o fracasso dos esforços de institucionalização da pesquisa científica no Brasil.

Embasados em Demo (2000) podemos dizer que a universidade deve confirmar papel imprescindível frente ao desenvolvimento humano, desde que o faça sob o signo da formação da competência, indicando a formação do cidadão capaz de intervir eticamente na sociedade e na economia, tendo como alavanca instrumental crucial o conhecimento inovador. Não pode, por isso, bastar-se como ensino, como é ainda regra geral entre nós. Pior que isto, não se sustenta a proposta de apenas ensinar a copiar, não só porque significa mero treinamento mas, sobretudo, porque implica inequívoca imbecilização.

Pierre Bourdieu ao longo destes múltiplos exemplos de exercício é, sem dúvida, dono de uma implacável sociologia crítica. A resposta para sua fúria de escrita corresponde a uma urgência na intervenção cívica, explícita na sua perspectiva, pelo conceito de habitus e de campus. Bourdieu, em toda a sua vida, tentou responder à pergunta "o que é um indivíduo?", procurando encontrar as margens de liberdade possível desse indivíduo contra os mecanismos sociais que o fabricam, e, ao mesmo tempo, o encerram.

Finalizando, podemos dizer que Peirre Bourdieu é um sociólogo francês fascinado por um imenso desejo de liberdade. Porém, tal como Bourdieu, Pedro Demo, sociólogo brasileiro de renome, pode ser considerado, um mestre da criticidade, da politicidade, mobilizado na sua escrita, em alguns casos, por uma ironia implacável e, em outros, por uma raiva surda que parecem denunciar as imensas negações e decepções com que suas aspirações se confrontam, e nós focamos nossas angústias embasados nesses autores, porque tal como eles, temos a certeza que a Universidade Brasileira precisa ser revista de alto a baixo no que diz respeito as suas funções neste início de século XXI, pois

las univeridades, a comienzos de este siglo, dejaron de representar el conocimiento de punta. Perdieron capacidad de garantizar el futuro suceso de sus alumnos.Yá no son centro de distribución de conocimiento y no son 
mas usadas como herramienta para unir a la humanidad. Las universidades corren el riesgo de naufragar éticamente (SUASNABAR:2005, p.101).

\section{REFERÊNCIAS}

BONNEWITZ, P. La Sociologia de Pierre Bourdieu. Buenos Aires: Ediciones Nueva Visión, 2006.

CASTANHO, S. A universidade entre o sim, o não e o talvez. São Paulo: Papirus, 2000

CATANI, Afrânio Mendes. A sociologia de Pierre Bourdieu.(s/e). 2002

CHAUÍ, M. Escritos sobre a Universidade. São Paulo: UNESP, 2001.

DEMO, P. Pesquisa e Construção de Conhecimento RJ: Tempo Brasileiro, 2000.

. Desafios Modernos da Educação. Rio de Janeiro: Vozes, 1996.

. Pesquisa: princípio científico e educativo. São Paulo: Cortez, 1996 b.

.Educar pela Pesquisa. SP: Autores Associados, 1996c.

.Politicidade - Razão humana. SP: Papirus, 2002.

.Argumento de Autoridade X Autoridade do Argumento. Rio de Janeiro: Tempo Brasileiro,2005.

FLACHSLAND, C. Pierre Bourdieu y el capital simbólico. Argentina: Campo de Ideas, 2005.

MASETTO, M. Docência na Universidade. SP: Papirus, 2006.

MORAIS, R. A Universidade desafiada. Campinas: UNICAMP, 1995.

PACHECO, E. Os Institutos Federais: uma revolução na educação profissional e tecnológica. Natal: IFRN, 2010.

SANTOS, B. La Universidad em siglo XXI. Buenos Aires: Laboratório de Políticas públicas, 2005.

SOUZA, P. LDB e Educação Superior: estrutura e funcionamento. São Paulo: Pioneira, 2001.

SUASNABAR, C. Universidad: reformas y desafios-dilemas de la educación superior em la Argentina y el Brasil. BA:Prometeo, 2005.

VIEIRA, S. A Universidade em questão. São Paulo: Cortez, 1995. 